Supporting information

\title{
Effect of nitrogen on the stability of Si nanocrystals produced by decomposition of alkyl silanes
}

\author{
Natalia Zaitseva, Sebastien Hamel, Zu Rong Dai, Cheng Saw, Andrew Williamson, and Giulia Galli
}

Lawrence Livermore National Laboratory, 7000 East Avenue, Livermore, California, 94551

SI-1. P-T diagram of (a) TES decomposition in the presence and absence of gold nanoparticles; lower temperature of the sharp pressure increase indicates a catalyzing effect of gold on the precursor decomposition process. (b) Pure TOA decomposition. The data were obtained in $100 \mathrm{ml}$ Parr reactor equipped for the pressure measurements.

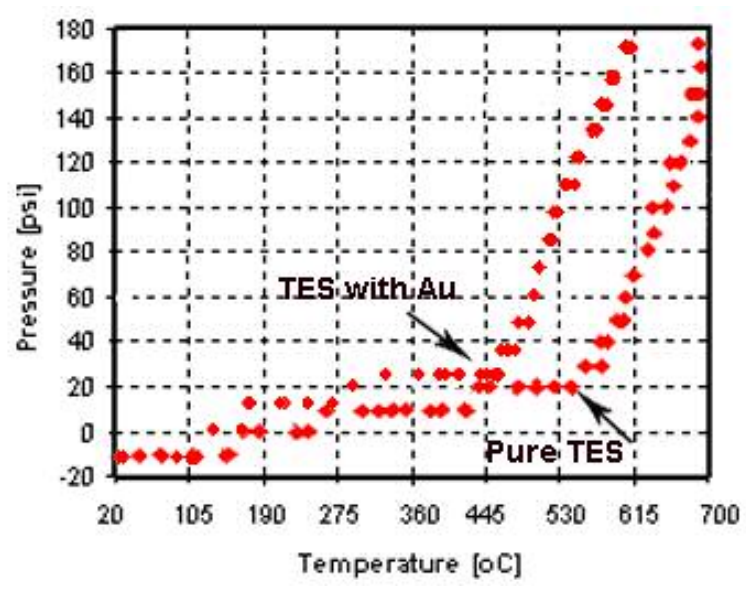

(a)

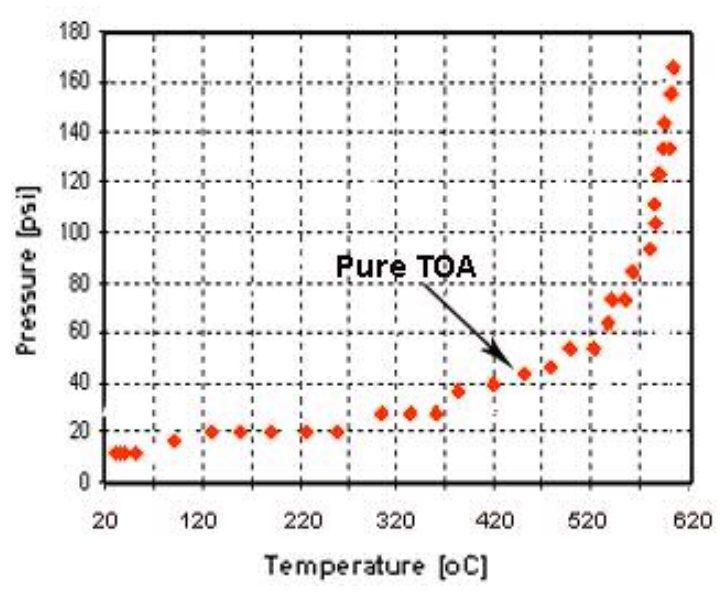

(b) 
SI-2. Typical photoluminescence spectra of the final powders produced by decomposition of TMS and TES; dispesions in DMF; excitation wavelength is $400 \mathrm{~nm}$.

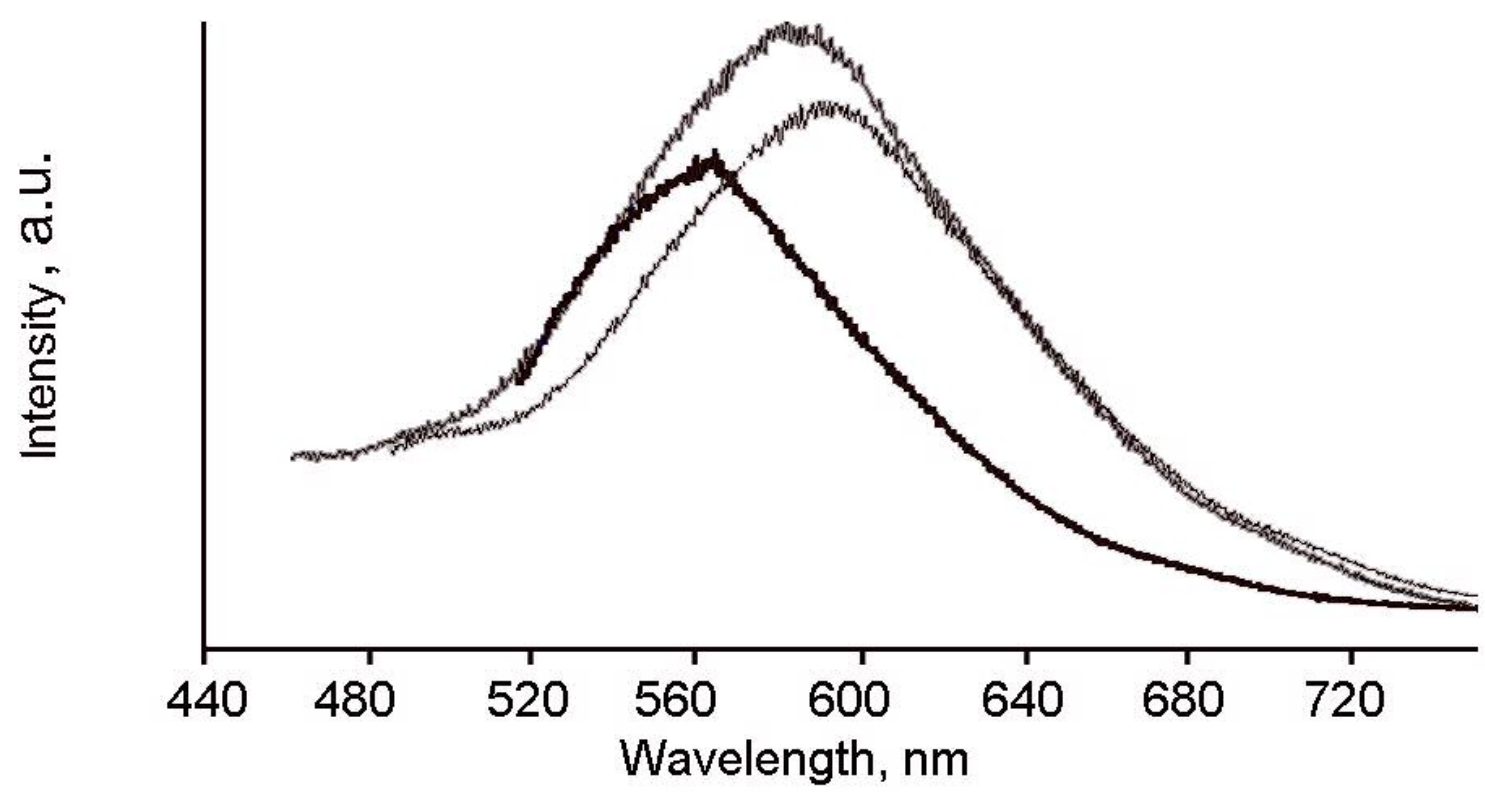


SI-3. TEM images and EDS patterns obtained from the final powders synthesized in two different experiments: (a) - no amines, one week of air exposure; (b) - sample synthesized in TOA, exposed to air as a dry powder during one year.

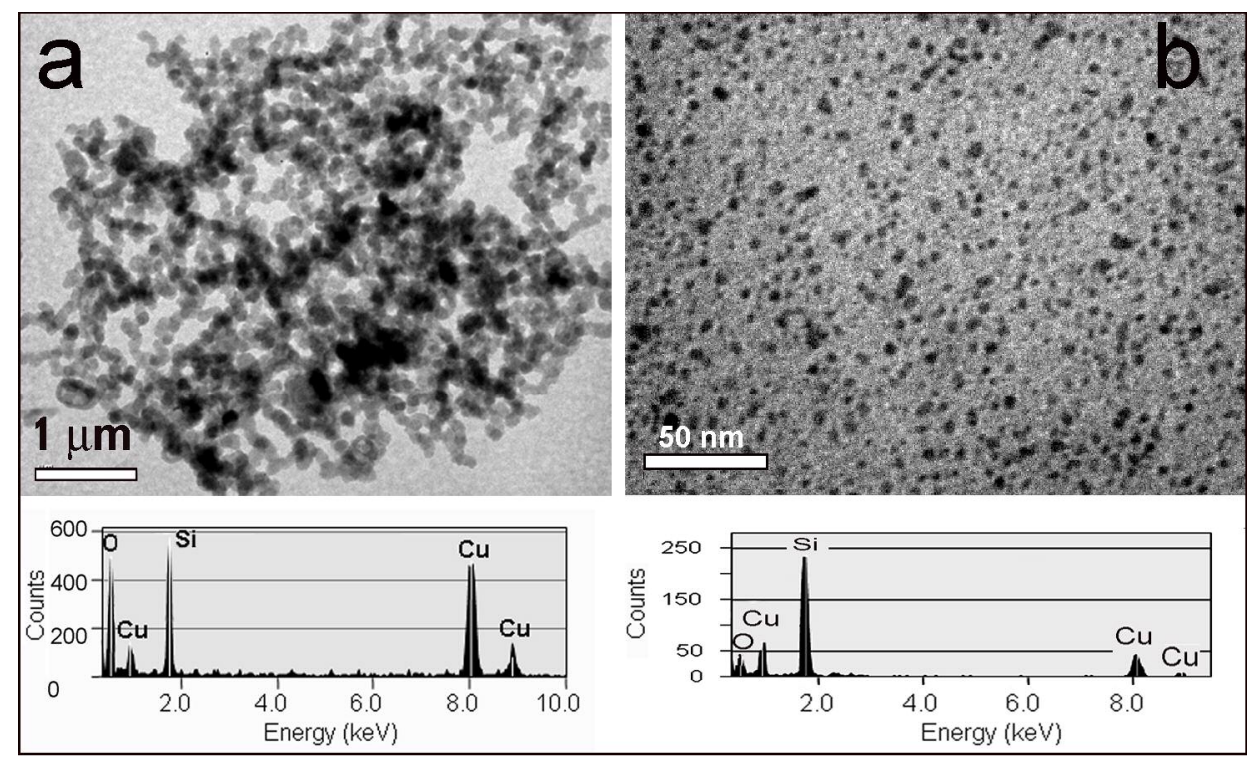


SI-4. Multiple coverage by amine and bridged groups. Calculated energy cost (-) or gain (+) for replacing a hydrogen by an amine group (top) and two hydrogens by a bridge group (bottom) on the surface of a $1 \mathrm{~nm}$ silicon cluster $\left(\mathrm{Si}_{35} \mathrm{H}_{36}\right)$. The hydrogen can be either on $\mathrm{SiH}_{2}$ site (summit) of a $\mathrm{SiH}$ site (face).

\section{Stability of amine groups}

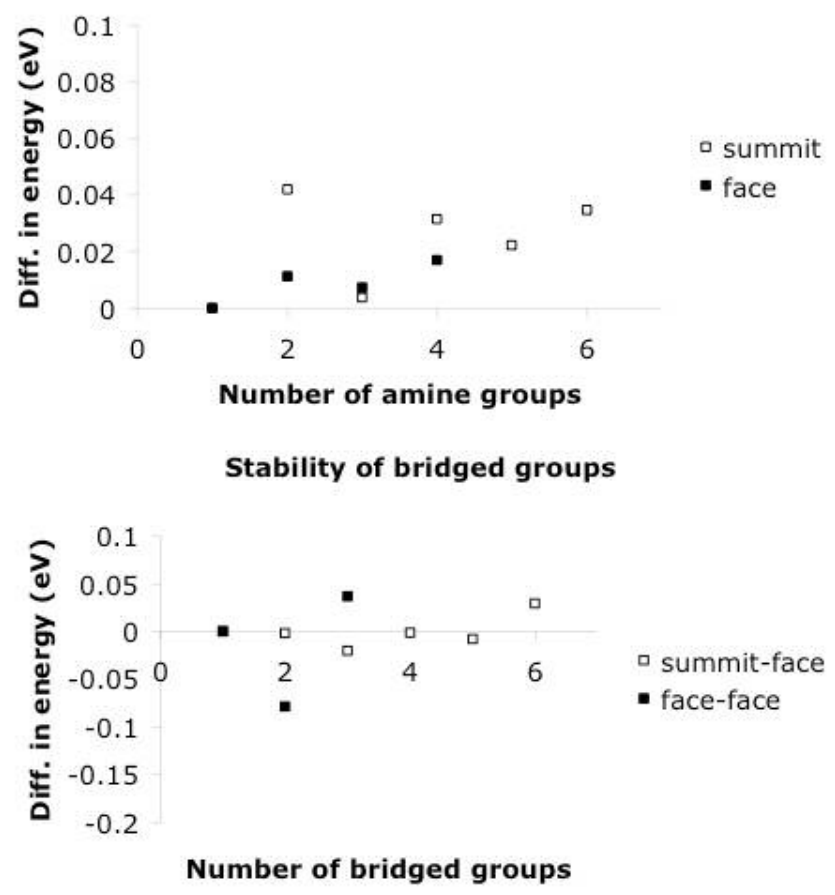


SI-5. Multiple coverage by amine and bridged groups. Change in the calculated energy gap with the number of amine (top), di-interstitial pair (middle) or bridged (bottom) groups on the surface of a $1 \mathrm{~nm}$ silicon cluster $\left(\mathrm{Si}_{35} \mathrm{H}_{36}\right)$.

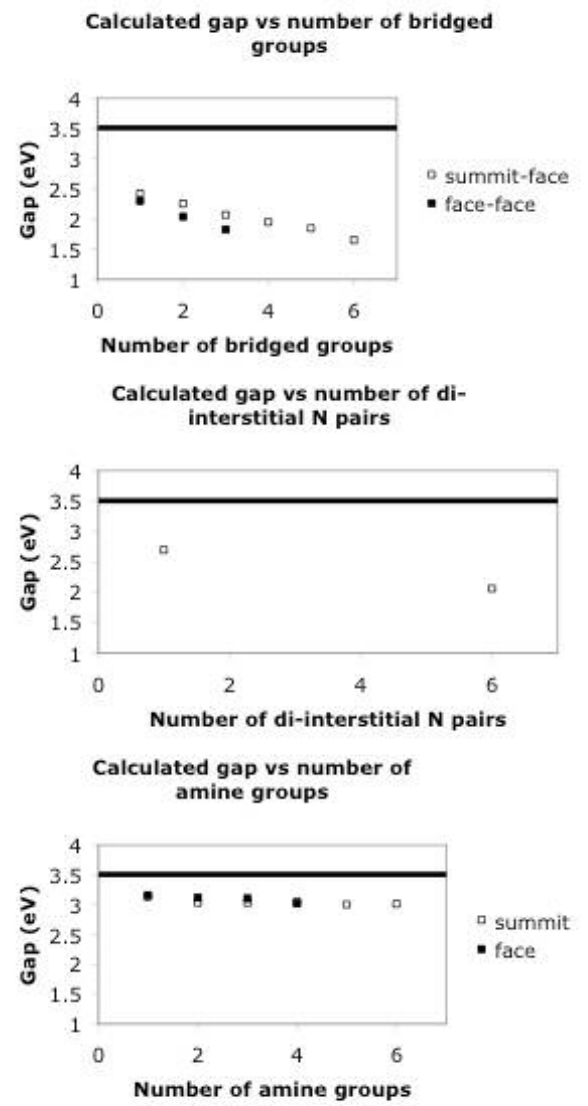

